\title{
DISEÑO E IMPLEMENTACIÓN DE UN SISTEMA DE TRATAMIENTO PARA LA REMOCIÓN DE ARSÉNICO DEL AGUA DE CONSUMO EN EL ALTIPLANO Y VALLES DE BOLIVIA
}

Ramiro Escalera, Omar Ormachea, Mauricio Ormachea, José Luis García, Jesús Suso, María Eugenia García, Fernando Pérez, Jorge Hornero, Oscar Fernandez, Ana Zelaya, Lizángela Huallpara

\section{RESUMEN}

La presencia de elevadas concentraciones de arsénico encontradas en el agua de consumo de dos sitios geográficamente distantes en Bolivia, ha requerido el diseño, la construcción y la implementación de un sistema de remoción de arsénico para así obtener agua más segura para su consumo. Uno de los sitios se encuentra en una unidad educativa de la zona periurbana de la ciudad de Cochabamba y el otro en una escuela rural en la población de Quillacas en el departamento de Oruro dentro del área del Altiplano boliviano. El sistema consta de dos procesos de remoción de arsénico que funcionan en serie: i) el proceso RAOS que requiere una etapa de aireación y dosificación con sulfato ferroso y citrato de sodio automáticamente controlado con el flujo de agua, 6 fotoreactores provistos de tubos de acrílico de alta transmitancia emplazados en colectores solares tipo Fresnel (con capacidad colectora equivalente a 17,5 soles) y ii) el proceso IHE-ADART que utiliza filtros de arena recubierta con óxido de hierro, IOCS, seguidos de una microfiltración con filtros de polipropileno de 5 y 1 micras dispuestos en serie. El sistema es capaz de remover el arsénico total (particulado y disuelto) hasta concentraciones menores a lo requerido por la guía de la Organización Mundial para la Salud (OMS) y la norma boliviana para agua potable (NB 512) (10 $\mu \mathrm{g} / \mathrm{l}$ ) en ambas unidades educativas, aun cuando las características hidroquímicas de las aguas tratadas fueron sustancialmente diferentes. Las características del agua de pozo en Cochabamba, favorecen la remoción de arsénico hasta en un $75 \%$ por ambos procesos, especialmente el $\mathrm{pH}$, el potencial óxido-reducción y las bajas concentraciones de aniones competidores (cloruros, sulfatos y nitratos) por los sitios de adsorción que están sobre la superficie de los microflóculos de hidróxido férrico o de la capa de óxido férrico que recubre la arena de los filtros IOCS. Por otra parte, las elevadas concentraciones de cloruros, boratos y sulfatos presentes en el agua de pozo que usa la unidad educativa de Quillacas y su alta salinidad no afectan significativamente a la capacidad de adsorción de la arena IOCS, permitiendo elevadas eficiencias de remoción de arsénico (mayores al 90\%). En conclusión, el sistema es adecuado, desde el punto de vista técnico para la remoción de arsénico natural presente en aguas subterráneas del valle bajo de Cochabamba y de la zona sur colindante con el lago Poopó en el altiplano boliviano.

Palabras Clave: Remoción de Arsénico, RAOS, Filtros de Arena Recubierta de Óxido De Hierro, Agua Subterránea, Fotocolectores Tipo Fresnel.

DOI: 10.23881 /idupbo.020.1-2i 